\title{
KLAVIRSKI OPUS SLAVKA OSTERCA
}

\author{
Andrej Rijave c (Ljubljana)
}

Osterčeva klavirska dela ne pomenijo težišča skladateljeve ustvarjalnosti, čeprav njegov klavirski opus nikakor ni majhen. Če izvzamemo Tri skladbe za četrttonski klavir, od katerih je v celoti ohranjena le prva preludij - in del fuge in ki so glede na svojo enkratnost samo obrobnega pomena, saj so bolj rezultat obiskovanja četrttonskega kursa pri Aloisu Hábi kot pa organski člen $\mathrm{v}$ njègovem skladateljskem razvoju, obsega Osterčev klavirski opus osemnajst bibliografskih enot. Skladb je seveda precej več, ker večina biblioğrafskih naslovov predstavlja bolj ali manj obsežne zbirke, pa četudi krajših kompozicij. Kljub temu so vredne pozornosti, saj so bili skladateljevi prvi kompozicijski poizkusi posvečeni temu instrumentu. Razen tega je Osterc vedno znova, vse do svoje smrti skladal za klavir, ki mu sicer ni »ležal«, in s tem ustvaril kontinuiteto, na podlagi katere je možno slediti oblikovanju njegovega glasbenega jezika. Kot študijsko gradivo je klavirska partitura $v$ ta namen vedno najbolj pregledna, če se hoče razmeroma hitro in konkretno prodreti $\mathrm{v}$ strukturo in stilne značilnosti kompozicijskega stavka nekega skladatelja, ne da bi bile s tem seveda zaobsežene vse njegove komponente. Osterčeve klavirske kompozicije glede na celoten skladateljev opus sicer ne zasedajo takih ključnih pozicij kot na primer pri Arnoldu Schönbergu klavirski opusi $11,19,23,25$ in 33 , vendar pa jasno osvetljujejo posamezne njegove razvojne faze. Njihova obdelava naj torej prispeva $k$ razjasnjevanju Osterčevega skladateljskega lika, da se bo mogel polagoma izviti iz spominov sodobnikov in vse preveč globalne presoje ter vtisov njegovih naslednikov.

Prve ohranjene klavirske skladbe ${ }^{1}$ - Impresije (pred 1925) in Sonatina (1924) — so iz skladateljevega prvega razvojnega razdobja, ko je v letih od 1922 do 1925 poučeval v Celju in ko je z naraščajočo produkcijo in talentom vse bolj opozarjal javnost na svojo ustvarjalno moč. ${ }^{2} \mathrm{Z} e$ naslov prve zbirke je značilen in že na zunaj odseva nekatere stilne značilnosti posameznih skladb. Te pa, s svojimi naslovi - Spominski list, Hrepenenje, Nokturno, Valse, Erotikon, Impromptu, Pustni ples - ka-

1 C̆e ni drugače navedeno, se opiram na skladateljeve rokopise, ki jih v glavnem hrani NUK v Ljubljani.

2 Omenjeni skladbi je izvedla Tinka Apihova na skladateljevem »Kompozicij. skem koncertu« 2. marca 1925. Prim. Pokorn D., Slavko Osterc, Ljubljana 1965, 17. 


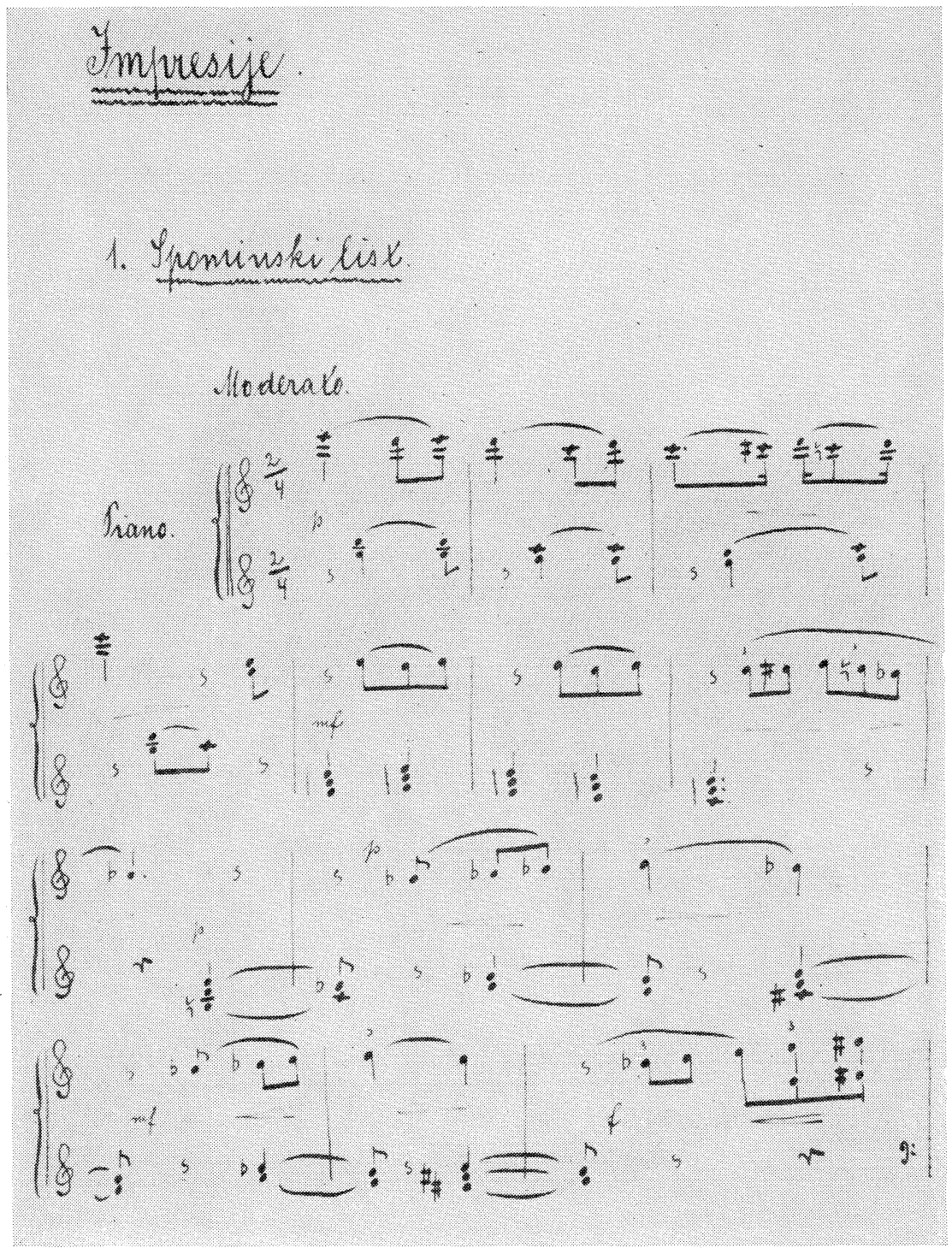

Začetek skladbe Spominski list S. Osterca

žejo na še starejšo, romantično tradicijo, saj gre, z eno samo izjemo, za tridelne karakterne skladbe $\mathrm{v}$ najmanjši možni obliki - miniaturi. Skladbe niso stilno enotne in se tudi med seboj glede tega razlikujejo: zdaj so bolj v ospredju impresionistične karakteristike, zdaj romantične ostaline, pri čemer se tu in tam že kažejo poteze, značilne za skladateljevo zrelo razdobje. 
Impresionistično še najbolj čista kompozicija je prva — Spominski list. Razen gradacije v srednjem delu, ki jo doseže s priljubljenim sekvenciranjem, pa še to sloni $\mathrm{v}$ tem primeru na celotonskih postopih melodične linije in )nevtralnih ( zmanjšanih trizvokih, ki zopet stopnjema rastejo za cel ton više, je celotna kompozicija statičnega značaja. Ne vodi nikamor. Izhodiščna melodika je nerazvita, neizoblikovana, brez vzgona in usmeritve. Mudi se $\mathrm{v}$ okviru velike terce in dopolnjuje vzporedno postope basa v sekstah. Očiten je tudi akordni paralelizem. Vendar pa skladatelj ne vzdrži izhodiščne stilnosti do konca. $\mathrm{Z}$ dominantnim septakordom $\mathrm{z}$ zadržano seksto, ki mu je tudi sicer $\mathrm{v}$ celotni zbirki zelo pri srcu, jo prav banalno zaključi. V nadaljnjih kompozicijah se posamezni elementi, ki so značilni za impresionistični stavek, še pojavljajo; tako vzporedna akordika, uporaba zvečanega trizvoka, celotonske lestvice, tudi $\mathrm{v}$ tercah, vendar ne več za ustvarjanje osnovnega, impresionističnega vzdušja, ampak samo za dosego prehodne barvitosti, tonalne nedoločljivosti in kontrasta $\mathrm{v}$ klavirskem stavku, ki se, skromen in nezahteven, sicer giblje pretežno v vodah romantične tradicije. Melodika raste iz harmonije ter v »Più mosso (c Nokturna, ki je najmanj invenciozna skladbica zbirke, mestoma seže celo nazaj do Chopina. Moduliranje in kadenciranje je skoraj brez izjeme razložljivo v okviru klasičnih harmonskih stopenj. Vendar pa tonalitete niso eksplicitno označene na začetku posameznih skladb, saj je kljub avtentičnim in plagalnim kadencam, s katerimi jih večinoma zaključuje, glasbena govorica že na meji, ki bi v okviru ene skladbe dopustila dosledno uvrstitev v karakterističen dur ali mol. So sicer izjeme kot na primer Hrepenenje ali Erotikon, ki obe sodita v G-dur. Če je glasbeni jezik v Hrepenenju, Erotikonu in Impromptuju harmonsko najbolj bogat, tja do najraznovrstnejših septakordov, njihovih obrnitev ter nonakordov, pa so Impresije kot celota ritmično skromno diferencirane.

Najbolj zanimivi v zbirki so seveda tisti momenti, ki odkrivajo posamezne črte kasnejših Osterčevih kompozicijskih naziranj. Tu in tam, vendar kot še zelo redko izjemo, doda skladatelj kakšno sekundo posameznim harmonijam ali tonom. Presenetljiv je tudi zaključek z varljivo kadenco molovske tonalitete, ki z Impromptujem nima sicer nobene zveze. Pomembno je dalje dejstvo, da prvič v skladbi Valse in nato še v Erotikonu prenaša posamezne motive iz roke $\mathrm{v}$ roko, se pravi iz enega glasu $\mathrm{v}$ drugi, kar kaže že na začetke preproste imitacije in polifonskega mišljenja, ki je tako značilno za skladateljevo zrelo razvojno fazo. Poleg Spominskega lista, ki je izrazito impresionističen, sta izven romantične stilnosti zbirke le še oba plesa: motorično živ, izrazito sekvenčno grajeni Valse in povečini v vzporednih kvintah komponirani Pustni ples. Mirnejši motiv slednjega spominja po svojem značaju, vzporednih harmonijah in melodiki na prvo skladbo zbirke; nikakor pa ne kadenca, ki poslušalca zopet preseneti: prvotno, zaradi izpuščene terce, nedoločeno izhodiščno sozvočje pripelje skozi subdominanto in sedmo stopnjo naravnega mola $\mathrm{v}$ istoimenski dur.

Sonatina se od skladbic v Impresijah loči predvsem po svoji dolžini. Tudi sicer je to najobsežnejša skladateljeva klavirska kompozicija, ki pa je Osterc na takratni stopnji svojega razvoja in s svojim takratnim znanjem formalno še ni obvladal ter ji zato tudi ni znal podeliti potrebne 
enovitosti. Nalogo si je otežil še s tem, da jo je zasnoval kot enostavčno kompozicijo. Kako jo je formalno rešil, pokaže analiza njene strukture: množica kratkih delov, ki jih ne moremo označiti kot stavke, ampak kvečjemu kot odstavke, si brez pavze sledijo drug za drugim. Tako nastane veriga drobnih glasbenih členov, ki so si po fakturi, dinamiki, ritmu in tempu, katerega sproti predpisuje in spreminja, med seboj različni. Oblikovna formula, ki bi jo izrazili s črkami, bi zahtevala skoraj polovico abecede in bi tudi s te strani poudarila njeno mozaičnost. Kar ponuja se analogija $\mathrm{z}$ renesančno sonato, $\mathrm{v}$ kateri si $\mathrm{v}$ nizu kontrastirajo vedno nove, kratke glasbene misli, ki jih skladatelj obsežneje ne razvija, ampak samo nakazuje. Temu principu gradnje je Sonatina na moč podobna, pri čemer prihaja seveda tudi do ponovitev istih ali po značaju vsaj podobnih členov. Posameznih idej pri tem ne preoblikuje. Prenaša jih samo iz roke v roko, na nove stopnje. Nato pa oblikuje nov člen, ki prejšnjemu kontrastira. Celo táko oblikovanje glasbenega tkiva, kot ga kažejo naslednji takti, kjer $\mathrm{v}$ zadnjih dveh zasledimo skromno variirano in deminuirano linijo basa prejšnjih dveh taktov, so izjemni:

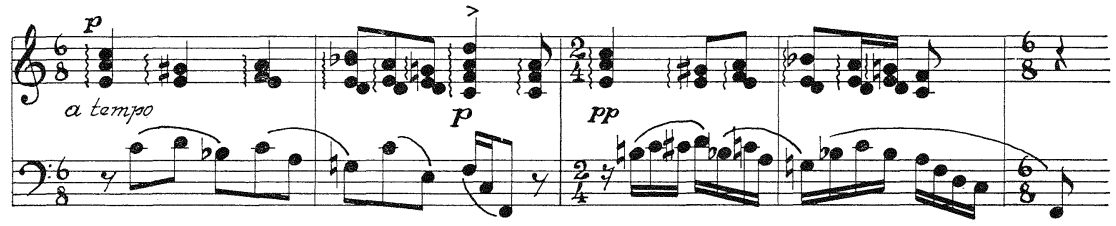

Ob Sonatini se lahko govori o bogati skladateljevi invenciji oziroma o materialu, ki bi ga bilo treba skoncentrirati in združiti v enovitejšo celoto. Táko, kot je, ne more rešiti niti večkrat $\mathrm{v}$ kompoziciji ponovljeni motiv treh izhodiščnih akordov desne roke, ki bi jim mogli iskati korenine v kakšni »idée fixe ( 19. stoletja, seveda brez programskih namer. Stilnost Sonatine je tako glede tradicije kot iskanja novega podobna tisti v Impresijah, le da ni zaslediti impresionističnih značilnosti. Klavirski stavek je vsekakor zahtevnejši, zlasti $v$ členih, ki so etudno-pasažnega značaja. Ne manjka že $v$ Impresijah omenjenih polifonskih prijemov in tudi ne izrazite romantične spevnosti:

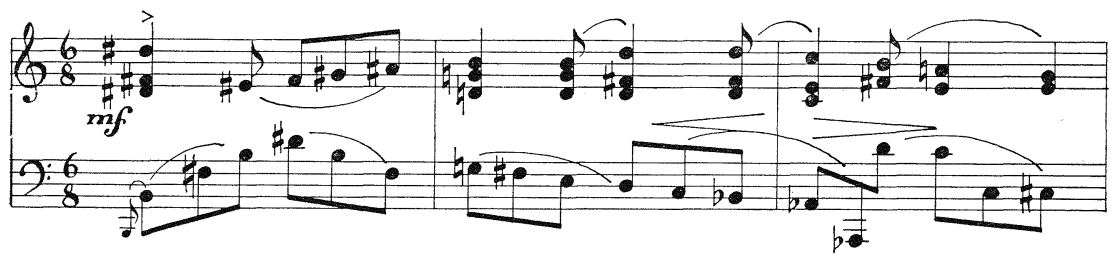

Impresije in Sonatina kažejo skladatelja, ki se je znašel v dvojni dilemi. Na eni strani se je zavedal, da mu manjka še precej teoretičnega znanja, na drugi strani pa ga je gnala želja po neizhojenem, novem. Oboje mu je izpolnil študij v Pragi (1925-1927), kjer so, kot je znano, nanj najbolj vplivali avantgardni nazori dveh profesorjev - Aloisa Hábe in Karla Boleslava Jiráka. 
Stilni preobrat, ki ga je povzročil praški študij, odlično ponazarjata Dve miniaturi iz leta 1927: Mala koračnica ${ }^{3}$ in zlasti Valse lente. ${ }^{4} \mathrm{Naj}$ rabi slednja kot primer. Odpre se nov, atonalni svet, iz katerega so izginili principi funkcionalne harmonije. Zato pa je disonanca - v vertikali in horizontali - dobila samostojno ekspresivno kvaliteto. V melodični liniji prevladujejo čiste kvarte, velike septime oziroma zmanjšane oktave, male septime, medtem ko ni nobene terce. Ko nastopijo sekundni postopi, jih skladatelj veže skoraj izključno $\mathrm{v}$ kvartna sozvočja, ki so $\mathrm{v}$ tem valčku značilna in izrazita. Uporabi tudi njihove obrnitve in akordom doda po kakšno sekundo. Problem odkrivanja )tematičnega(c materiala in njegovega razlikovanja od sekundarnega ali prehodnega gradiva, ${ }^{5}$ problem, ki ga je treba $v$ vsaki atonalni skladbi brez opore $v$ tonalnih oblikovnih principih reševati vedno znova, $v$ Valse lente nikakor ni težak. Jedro osnovne misli stoji jasno na začetku:

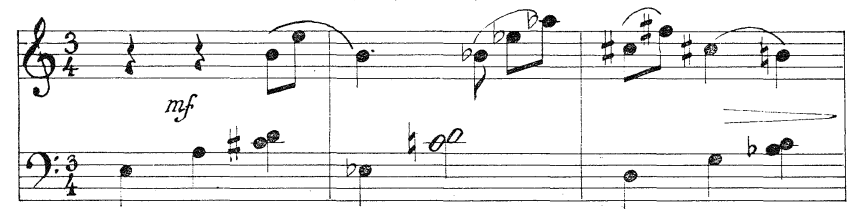

V okviru ostale, disonantnejše fakture skladbe in glede na lastno kvartno strukturo ima konsonanten značaj, tako da skupaj s svojim manj izrazitim nadaljevanjem ustvarja nekakšno »tonalno« oporišče. Obenem rabi tudi kot formalni element, saj ga sredi kratke kompozicije skladatelj skoraj v celoti, nevariiranega ponovi za sekundo više. Tako se načela tradicionalne gradnje, kjer se s ponavljanjem poudari tisto, kar je važno in identično, nadaljujejo tudi v skladateljevem tretjem razvojnem obdobju, ko se je po povratku iz Prage za stalno naselil v Ljubljani.

Kljub osnovni usmerjenosti $v$ atonalnost je tudi $v$ nadaljnjem klavirskem snovanju zaslediti povezovanje raznovrstne tradicije $\mathrm{z}$ novimi naziranji. V tej smeri je zelo poučna Dvoglasna suita (1928), ki sestoji iz Preludija, Valčka, Uspavanke in Male fuge. Zavoljo mejnih stavkov bi se formalni vzori lahko iskali $\mathrm{v}$ baročni suiti, čeprav je bila zaključna giga bolj običajna. Značilna pa je vključitev valčka in uspavanke, teh v romantizmu kar modnih oblik, in to $\mathrm{v}$ tridelni obliki, ki jo izkazuje tudi preludij. S stilnimi epitetoni je možno pristopiti še z ene strani: dvoglasje, skupaj s pregledno fakturo in jasno gradnjo ustvarja pravo klasicistično oziroma neoklasicistično prozornost. Glasbena govorica je $\mathrm{v}$ osnovi atonalna in enakovredno tretira vse tone kromatične lestvice, čeprav pri tem izstopajo po tradiciji disonantni intervali, zlasti kvarta. Atonalno najbolj dosleden je kanonično zgrajeni Preludij. Tudi Valček ima trden vezni element $\mathrm{v}$ osnovnem, ponavljajočem se kvartnem motivu: zmanjšana kvinta, tri čiste kvarte, zmanjšana kvinta. In vendar skladatelj zaključi

3 Objavljena v Novi muziki I/1928, priloga »Mala nova muzika« št. $1,3$.

4 Objavljena v Novi muziki I/1928, priloga »Mala nova muzika« št. 5, 8.

5 Perle G., Serial Composition and Atonality, London 1962, 9. 
kodo $\mathrm{z}$ avtentično kadenco — $\mathrm{s}$ presenečnjem, ki je po efektu podobno varljivim in samovoljnim zaključkom $\mathrm{v}$ prvem ustvarjalnem obdobju, a s to razliko, da je tam uhajal iz tonalnosti, tu pa se vanjo vrača. Mala fuga je majhna samo glede števila glasov, nikakor pa ne po svoji dolžini in formalni gradnji, ki izkazuje vse obvezne dele, kakor tudi ne po obsežni, izraziti temi. V njej uporabi vseh dvanajst tonov kromatične lestvice, ne da bi se izogibal ponavljanjem:

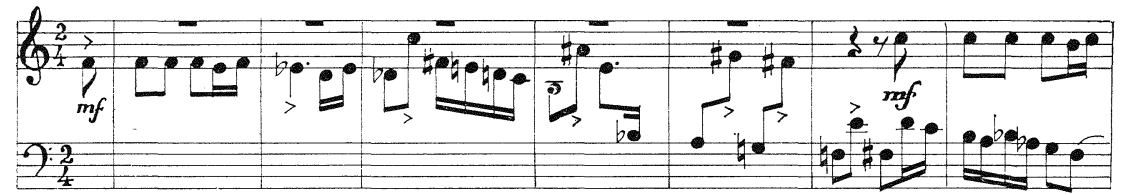

Opozoriti pa je na dva momenta, ki kažeta na prepletanje atonalnega $\mathrm{z}$ načeli, ki veljajo $\mathrm{v}$ klasičnih fugah. Tako si dux in comes odgovarjata realno v kvinti. Še bolj značilno pa je dejstvo, da je večji del reprize zgrajen na ritmiziranem pedalnem tonu, na dominanti, ki pripravlja zaključno avtentično kadenco, tako da jo koda samo še potrdi.

Naslednje leto, leta 1929, je Osterc napisal Interludij, ki je transkripcija tretjega stavka iz Partite za violoncelo in klavir, ter Male preludije. Če v Interludiju izvzamemo kvartne harmonije, sta obe deli linearno zasnovani. Preludije, vseh je pet, bi mogli označiti kot tekoče, ritmično enakomerno pulzirajoče konstruktivistične študije $\mathrm{v}$ linearnem vodenju glasov. Vsi, razen srednjega, so namreč kanoni, pri čemer gre pri prvem povrhu še za kanon $\mathrm{v}$ inverziji. Intervali so seveda emancipirani, ne da bi skladatelj posebej iskal ali vztrajal na disonantno ostrejših. Zanimivo pa je, da $\mathrm{v}$ vseh preludijih $\mathrm{z}$ uporabo intervalov kvinte, kvarte, oktave ter vodilnih tonov jasno kadencira in ustvarja trden zaključek na tonu, ki pa, kar je zopet značilno, ne pomeni vedno tudi tonalnega središča kompozicije. Srednji preludij je poseben primer in še bolj jasno odseva povezavo atonalnosti $s$ tonalnimi principi. Gornji glas je izrazito $v$ F-duru. Oblikovan je tako, da se z 19. taktom melodična linija v raku vrača $\mathrm{k}$ svojem začetku. Vendar ta »hin und zurück« ni popoln, ker je spodnji glas bolj svobodno oblikovan, čeprav na koncu izrazito poudari dominanto in se z obsežno kromatično pasažo zaključi na skupni toniki:

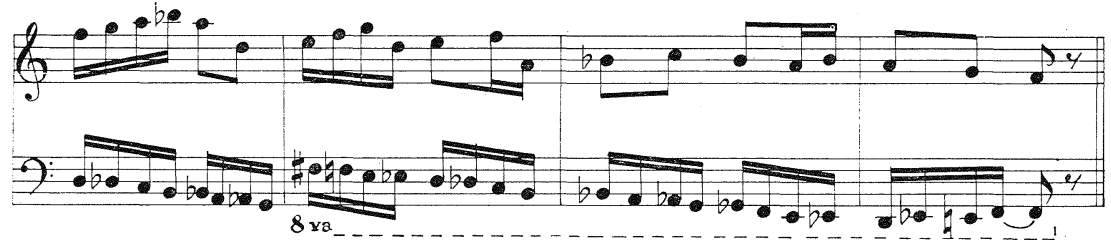

Če bi bila spodnja linija tonalno bolj izoblikovana, bi skladbo mogli uvrstiti v bitonalni okvir. Tako pa atonalna komponenta spodnjega glasu ne dovoljuje tako toge kategorizacije. Zvočni rezultat je namreč veliko bliže podobnim rešitvam v nekaterih Osterčevih samospevih, ki so diatonski $\mathrm{v}$ melodiki in atonalni $\mathrm{v}$ spremljavi. 
Nove značilnosti v Osterčevem klavirskem kompozicijskem stavku je zaslediti v prvi skladbi opusa Koral in fuga (1933), ${ }^{6}$ ki sta nastali po štiriletni prekinitvi v skladanju za klavir. Gre za poseben slog izražanja, ki ga v podnaslovih mnogih svojih, ne samo klavirskih, kompozicij skladatelj pobliže določa s pripisom »Kakor koral( ali »Quasi choral«. Njegovo bistvo je v počasnem tempu, enakomerno odvijajočem se sosledju akordov, pri katerih je melodija $\mathrm{v}$ najvišjem glasu. V obravnavanem Koralu je

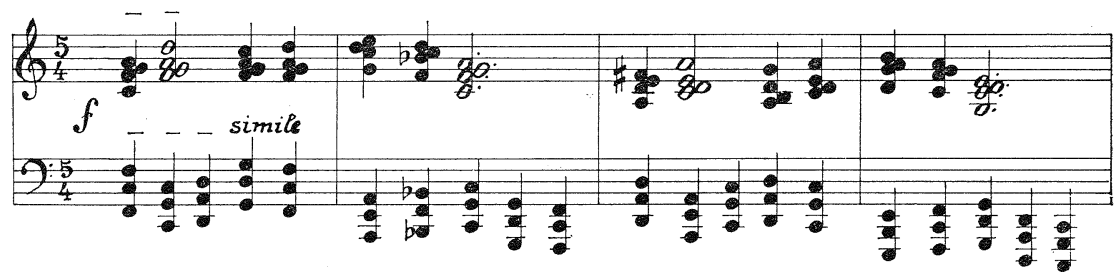

sekvenciranje bistveno sredstvo oblikovanja forme, ki zopet izpričuje tridelnost. Razen dveh kromatičnih izmikov je melodija diatonska ter kot bas sodi $v$ tonaliteto F-dura. Vendar je občutek tonalnosti zamegljen. Zavoljo vsaj dveh vzrokov: deloma zaradi dodajanja sekund posameznim akordom, ${ }^{7}$ s katerimi jih skladatelj zvočno nasičuje, veliko bolj pa zaradi dejstva, da sta akordna kompleksa desne oziroma leve roke razmeroma samostojna. Hočem reči: kakor imata, če jima sledimo vsakemu posebej, tonalno izrazito, funkcionalno kvaliteto, pa je ta pri sozvenenju močno načeta, saj se funkcionalne karakteristike enega in drugega kompleksa vedno ne pokrivajo, ker so »premaknjene(c. Kljub temu nas primerjava z ostalimi, podobnimi stavki Osterčevega klavirskega opusa pouči, da si je skladatelj ta slog zamislil izrazito homofonsko, kjer je vertikala bolj rezultat vsakokratne navpične zvočne rešitve in ne toliko posledica bolj ali manj svobodnih horizontalnih linij. Zato se zdi, da je bilo slednje hotenje $\mathrm{v}$ tem »koralnem ( stavku, zlasti v srednjem delu, bolj prisotno, kot je sicer. Harmonska analiza pokaže zelo raznovrstno podobo: od kvintakordov in obrnitev, mimo raznih nepopolnih non-, undecim- in tredecimakordov do kvartnih harmonij, s tem da so pri vseh teh kombinacijah sozvočja polnjena še z dodatnimi toni. - Fuga je po svojih karakteristikah podobna Mali fugi iz Dvoglasne suite; tako po obliki kot po intervalnem odnosu med duxom in comesom. Tonalno občutje pa je v tej živi skladbi močnejše, ne da bi mogli trditi, da je Fuga glede na Koral v paralelni molovski tonaliteti, saj že tema, gledana $\mathrm{v}$ celoti, niha med d-molom in D-durom in je $\mathrm{v}$ primerjavi s tisto $\mathrm{v}$ Dvoglasni suiti kar konservativna:
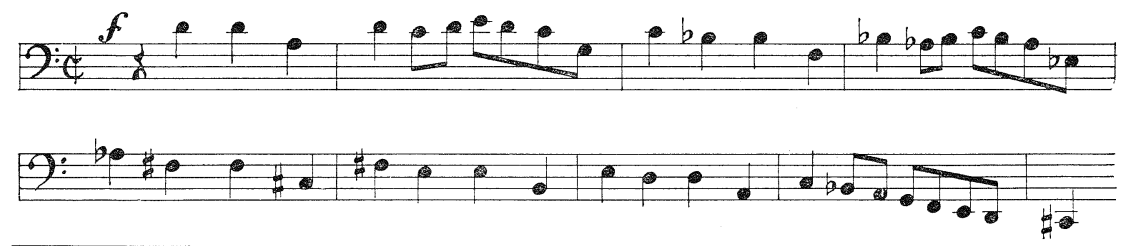

${ }^{6}$ Izdala in založila skladateljeva hči Lidija Osterc v Ljubljani 1942.

7 Persichetti V., Twentieth Century Harmony, London 1961, 109. 
Bagatele - Moderato, Valse, Allegretto, Koral, Allegro, ${ }^{8}$ ki so bile komponirane isto leto, imajo tipične značilnosti svoje zvrsti, s tem da izstopata tudi groteskna in sarkastična komponenta. To dosega Osterc z alteriranjem posameznih tonov, tako da so v opreki s tonaliteto, ki jo več ali manj jasno fiksira s kadenciranjem. Tako slonita na primer mejna dela valčka na diatonski ostinatni spremljavi, medtem ko je melodija grajena najprej iz čistih kvint, nato pa podana $v$ zmanjšani varianti istega intervala. Tako zbirka ne sodi niti $\mathrm{v}$ atonalni predal niti med tiste kompozicije, kjer moremo govoriti o bitonalnosti, ali kjer se atonalni principi povezujejo s tonalnimi, ampak v okvir svobodno, ali še bolje, svojevoljno tretirane tonalnosti. Kljub uporabi kvartnih pa tudi že sekundnih harmonij je tonalno središce skladb namreč vedno prisotno in se skladatelj vanj vrača. Večja navezanost na tradicijo se končno kaže tudi v nizanju štiritaktij, uporabi tridelne forme, simetrije, sekvenciranja.

Nov stilni premik v klavirskem kompozicijskem stavku prinese šele leto 1934, in sicer v dveh opusih: v Toccati in deloma v Arabeskah. Nikoli poprej, vsaj v klavirskem opusu ne, ni Osterc nakopičil toliko disonantnega zvoka, kot prav v Toccati. Nikoli poprej ni bila disonantnost tako kljubujoča in izsiljujoča. Ta hitra, v glavnem dinamično glasna kompozicija ima vse bistvene značilnosti klavirske tokate 20 . stoletja. Je motoričnega, homofonskega značaja. Principi polifonskega oblikovanja niso prisotni. Zato pa ne manjka ničesar — od kromatičnih pasaž in ponavljanja istega tona oziroma istih akordov $\mathrm{v}$ hitrem tempu do poudarka na

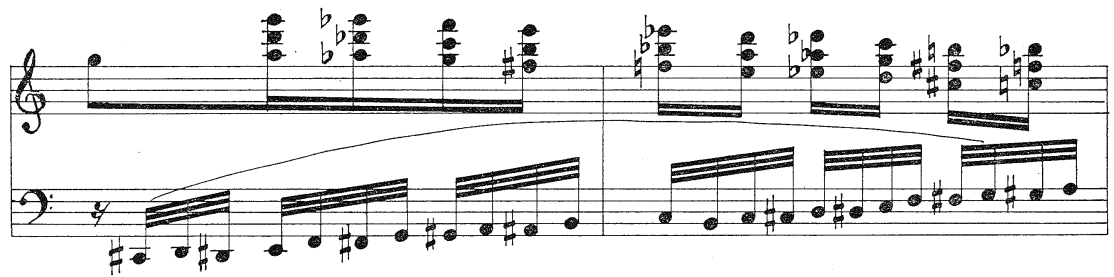

figurah, ki pa so v nenehnem nastajanju in spreminjanju. Poleg kvarte $\mathrm{v}$ horizontali in vertikali je očiten močan nagib $\mathrm{k}$ intervalom septime in none, zlasti velike septime in male none, ki sta po svoji kvaliteti bolj disonantni od ostalih dveh. Zvočna podoba tokate je jasna: giblje se $\mathrm{v}$ atonalnem prostoru, v katerega je vdrla tudi atematika. Pomemben pa je še en moment. Praksa dodajanja sekund akordom je $\mathrm{v}$ tej skladbi pripeljala Osterca tudi do harmonskih grozdov:

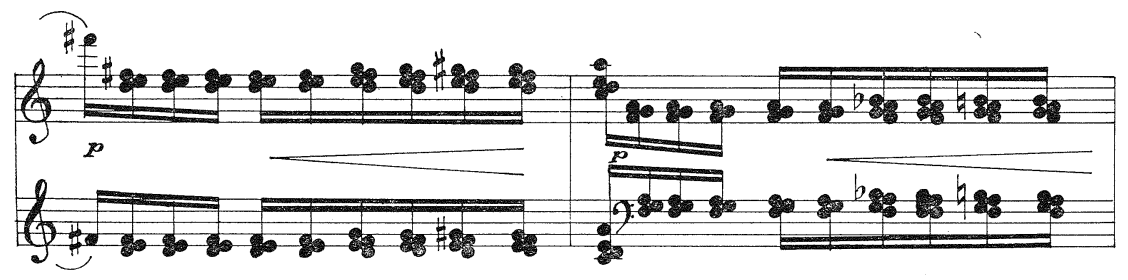

8 Skladatelj jih je v samozaložbi, brez zadnjega Allegra, izdal v Ljubljani leta 1941. 
Konec Toccate je zopet izrazito osterčevski: kljub nekaterim dodanim oziroma alteriranim tonom je zaključek možno imeti za avtentično kadenco.

Te in take kadenčne premike $\mathrm{v}$ smeri prehodnega ali končnega tonalnega centra je najti tudi v Arabeskah - Moderato, Allegretto, Tranquillo, Vivace, Grave, Presto. ${ }^{9} \mathrm{~V}$ četrti je možno celo govoriti o tonalnem središču na E. Nasprotni pol je predstavljen v tretji, v Tranquillu. Čeprav njena zaključna avtentična kadenca potrdi začetni ton in sama ruši atonalni značaj stavka, je $\mathrm{v}$ tej arabeski še najbolj, a tudi tu ne popolnoma, izpolnjena značilnost atematičnih kompozicij, namreč princip nerepeticijskega, na trenutnih asociacijah slonečega oblikovanja zvočnega tkiva. Nujna posledica je seveda svobodno, nesimetrično tretiranje forme. Te karakteristike so prisotne tudi $\mathrm{v}$ ostalih arabeskah, ki pa jih je $\mathrm{z}$ druge strani možno primerjati z Valse lente iz leta 1927. Tam je skladatelj sredi atonalne fakture ponovil celotno izhodiščno misel. Podobno se dogaja tukaj: ponovitve posameznih motivov, figur, akordov, harmonskih zvez in ritmov predstavljajo oprijemališča gradnje, pa tudi sīušnega dojemanja teh arabesknih iger $\mathrm{s}$ toni.

Kakor se je v desetih letih dvajsetega stoletja dunajska atonalna šola $\mathrm{v}$ okviru atonalnosti in atematičnosti zatekla $\mathrm{h}$ kratkim oblikam in tako reševala problem formalne gradnje, se je tudi Osterc nagibal $\mathrm{k}$ miniaturnim, včasih kar aforističnim formam. Razen tokate iz leta 1934, ki je izjemno obsežna, sestoji njegov zreli klavirski opus iz množice bolj ali manj drobnih, izrazno strnjenih skladbic oziroma stavkov. Zato naslov naslednje skladateljeve zbirke prav nič ne preseneča. To so Aforizmi (1936): $:^{10}$ Marcia, Moderato, Allegro, Moderato, Allegro vivace. Razen občasnih, že znanih reminiscenc strukturnih elementov je glasbeni jezik atematičen, $v$ celoti pa trši. Zato ni čudno, da $\mathrm{v}$ tem in takem disonantnem svetu zaključek zadnjega aforizma na zvečani kvarti zveni nevtralno in zato pomirjujoče. $\mathrm{V}$ zvezi z močnimi polifonskimi komponentami skladateljevega ustvarjanja, velja omeniti, da v Marcii rešuje vprašanje oblike z uporabo passacaglie: štiritaktna punktirana tema, ki se ponovi devetkrat - zadnjič $\mathrm{v}$ avgmentaciji v desni roki, nudi trden skelet za oblikovanje atonalne fakture $s$ tradicionalnimi sredstvi. Vendar pa je ta vezanost na tradicijo $\mathrm{v}$ zbirki izjemna.

Tako predstavljajo Pravljice (1937) njeno logično nadaljevanje v smeri čiščenja in izostrevanja glasbenega jezika, ki ga prevevajo intervali malih sekund, velikih septim, zmanjšanih in zvečanih oktav, malih non in podobno. $V$ takem zvočnem svetu se seveda nujno postavlja vprašanje kontrasta, ki je bistveno za vsako oblikovanje. V prejšnjih letih si je Osterc dovolil kratke, presenetljive ekskurze $\mathrm{v}$ tonalnost. Tukaj tega ni več. Zato pa postanejo razumljivi ekscesi $\mathrm{v}$ nasprotni smeri, $\mathrm{v}$ smeri iskanja novih možnosti izrabe zvoka. Glede na tako usmerjenost je na primer

9 Izdanja Univerzitetskog kamerno-muzičkog udruženja »Collegium musicum «, Beograd 1936, No. 4-5.

10 Iz istega leta je tudi Nokturno. Osnutka te kompozicije, ki naj bi ga po zbranih podatkih, ki mi jih je ljubeznivo dopolnil Danilo Pokorn, hranila Lidija Osterc, žal nisem zasledil. 
zahteval, da je $\mathrm{v}$ zadnji skladbi zbirke $\mathrm{z} \times$ označena mesta treba izvajati »z dlanjo po najnižjem kompleksu klaviature«:

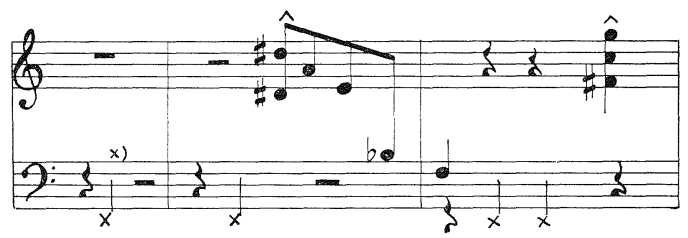

Vprašanje estetske opravičenosti in vsakokratne izpovedne nuje teh in takih mest je eno, ${ }^{11}$ drugo pa je dejstvo, da do tega Osterc ni prišel naenkrat. Začetki so $\mathrm{v}$ drobnih sekundnih sozvočjih, ki so z leti vse bolj brsteli, postali očitni v Toccati, tu pa dosegli stopnjo pravih clusterjev. In vendar Pravljice ( $V$ deveti deželi, O zlatolaskah, Kralj Matjaž, Pedenjčlovek-laketbrada, Intermezzo, Pravljica in resnica o svetovnem miru), ki nihajo na meji med resnostjo in neresnostjo, izpričujejo izredno bogat čustveni diapazon. Seveda je pri njihovi obravnavi, tako kot doslej, najbolj zanimivo in pomembno odkrivanje novih kvalitet, ki jih izkazujejo, kakor tudi tistega, kar jih veže na že izhojeno pot. $V$ tem smislu bi bilo potrebno omeniti način razvijanja misli, kakor jih razkriva druga pravljica, O zlatolaskah. Ponavljanje daljšega ali krajšega motiva se ne kaže vedno $\mathrm{v}$ njegovi dobesednosti, ampak $\mathrm{v}$ tem, da moremo tukaj slediti ponavljanju notnih vrednosti posameznih tonov $\mathrm{v}$ okviru posameznih taktov kakor tudi (ne vedno doslednemu) ponavljanju osnovne usmerjenosti tonov glede padanja in dviganja, čeprav se intervalne vrednosti pri tem spreminjajo; torej princip, ki deloma spominja na Bartóka in njegovo zmožnost izoblikovanja obsežne kompozicije iz enega samega jedra, sestoječega iz nekaj intervalov. Vsakršna nadaljnja primerjava bi bila seveda dvomljiva in predimenzionirana, saj so rezultati, ki jih je dosegel Osterc v tej smeri skromni $\mathrm{v}$ primerjavi $\mathrm{z}$ rezultati njegovega starejšega sodobnika.

Večje »drznostic in »avantgardnostic, kakor ju je izpričal v Pravljicah, Osterc ni dosegel. Še naprej je povezoval starejše z novejšim, tradicionalno s pravkar doseženim. Osnova je sevé ostala - atematičnost in atonalnost, ki je zdaj bolj )čista (c zdaj zopet nagiblje $\mathrm{k}$ bitonalnosti pa tudi tonalnosti. Topografski opis vsake posamezne skladbice bi sicer podrobneje določil njeno strukturo in stilnost, ne bi pa bistveno prispeval $\mathrm{k}$ osvetlitvi že povedanega. To velja za razmeroma umirjene Quatre miniatures (Moderato, Tranquillo, Valse, Choral-Lento - 1938), ${ }^{12}$ za Trois esquisses (Moderato, Tranquillo, Allegretto - 1939) ${ }^{13}$ kakor tudi za Six petits morceaux pour piano (Andante, Allegretto, Tranquillo, Tempo di valse, Andantino, Largo - 1940) ${ }^{14}$ in formalno jasno Fantaisie chromatique (1940), ki ni prav nič bolj kromatična od drugih kompozicij skladateljeve zrele razvojne faze. Zanimivo je pač omeniti, da je njen drugi sta-

\footnotetext{
11 Prim. Lipovšek M., Slavko Osterc, SGR I/1952, št. 2, 42-43.

12 Izdala Glasbena Matica, Ljubljana 1938.

13 Rokopis hrani Francka Rojec-Ornikova.

14 Izdal Mladinski pevski zbor »Vilhar« na Rakeku, Ljubljana 1940.
} 
vek - Moderato - zgrajen na kanonični inverziji diskanta tako, da začne bas po presledku enega takta za čisto undecimo niže. Za začetek vplete Osterc tudi kompletno dvanajsttonsko serijo, četudi jo potem ne uporablja kot nedotakljiv in nespremenljiv model za nadaljnje oblikovanje, ampak kot napoved bolj ali manj svobodne obravnave poltonov kromatične lestvice:

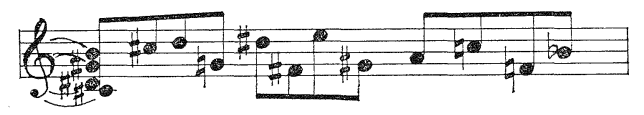

Zadnji klavirski opus - Petites variations $(1940)^{15}$ — sestavlja osem variacij, od katerih je osma, razen zadnjega takta, s katerim kadencira $\mathrm{v}$ Es-dur, popolna ponovitev teme. Osemtaktna struktura, z izjemo za en takt daljše šeste variacije, je $v$ celoti ohranjena in daje zbirki oblikovno jasnost in trdnost. ${ }^{16}$ Tematična linija je ves čas prisotna, če že ne $\mathrm{v}$ celoti ( tudi $\mathrm{v}$ inverziji) pa vsaj $\mathrm{v}$ njenih bolj ali manj popolnih intervalnih odnosih. Variacije dokazujejo, da je bil Osterc zmožen preoblikovanja posameznih glasbenih misli, tako da iz njih nastanejo nove in $\mathrm{v}$ novem kontekstu; princip, ki je bil v drugačni varianti nakazan že v pravljici O zlatolaskah. Dejstvo je namreč, da je ravno ta kvaliteta v Osterčevem klavirskem opusu zelo redka. $\mathrm{V}$ tonalni in $\mathrm{v}$ atonalni fazi pozna tako ponavljanje posameznih strukturnih elementov kot tudi sekvenciranje. Vendar: če pred odhodom v Prago še ni obvladal tehnike preoblikovanja, pa kaže, da je tako transformiranje postalo $\mathrm{v}$ njegovem zrelem obdobju glede na nova, atematska estetska naziranja, če že ne brezpredmetno, vsaj zelo malo uporabno. $\mathrm{V}$ atonalnem, atematičnem obravnavanju vseh dvanajstih poltonov se je pač najbolje počutil. Tak pristop, pri katerem je moral ob vsakem novem opusu vedno znova poiskati nove zvočne rešitve, ne da bi se popolnoma opredelil za katero koli izmed evropskih šol, ki so jih predstavljali klasiki prve polovice 20. stoletja, je bil za Osterca tipičen. Odkriva ustvarjalca, ki je iskal svojo pot, jo našel, pri njej vztrajal in jo tudi zavestno izoblikoval.

\section{SUMMARY}

Though Slavko Osterc (1895-1941) is one of the most important Slovene composers of the 20th century and among the most eminent modernists in the period between the two wars, the appreciation of his work has been based too much on the recollections of his contemporaries and has consisted mainly of general impressions of our time. The intention of the present article is to be a contribution towards a more concrete elucidation of his composition technique and style and, in this way, also of his personality. The subject of the article is his piano compositions. If the works for the quarter tone piano are excluded, there remain 18 bibliographical entries; however, the number of compositions is considerably

15 Izšle v skladateljevi samozaložbi v Ljubljani 1941.

16 Barry W., Form in Music, Englewood Cliffs, N. J. 1966, 303 sl. 
higher because most of the entries comprise sizeable collections. As his first attempts in composition are devoted to the piano, and because he wrote for this instrument - although it was not in the centre of his creative field - all his life, we have a complete continuity for our analysis. Early experiments belong in the sphere of the belated romantic tradition. Some compositions, however, reveal distinctive impressionistic idiom with parallel chords, augmented chords and the whole tone scale and so on. The stylistic turning point in his technique of composition was conditioned by his two years' study in Prague where he was, for the greater part, influenced by the progressive ideas of Alois Hába and Karl Boleslav Jirák. The composer enters a new atonal sphere where all principles of functional harmony have disappeared. Consequently, dissonance, both vertical and horizontal, assumed an independent, structural and expressive quality. So when the form and texture (particularly the polyphonic treatment of parts) are considered, neoclassical and neobaroque traits are found to be displayed. The harmonic idiom of Osterc in his mature period can be very varied. Thus he employs chords by thirds, fourths, added-note chords, chords by seconds and also clusters and compound harmonies which implies always an atonal basis. The latter is sometimes more "pure« and sometimes it inclines to bitonality and even tonality. When the dodecaphony is regarded, we also observe in some places, a complete series of twelve tones, although it is not employed as an unchangeable and untouchable model for his further work, but only as an annunciation of a more or less free treatment of the semitones of the chromatic scale. Thus, Osterc is a composer who seeks to find in each new opus a new solution of sounds and who goes his own way rather than onesidedly following any one of the mainstreams represented by the modernists of the first half of the twentieth century. 